\title{
Perinatal outcomes in young women with breast cancer and
} pregnancy

\author{
Ana C. Arteaga-Gómez, ${ }^{*}$ Gabriel Vázquez-Castellanos, ${ }^{1}$ Cintia Ma. Sepúlveda-Rivera, ${ }^{1}$ \\ Leticia Rocha-Zavaleta² and Enrique Reyes-Muñoz ${ }^{3}$ \\ 'Oncology Department, Instituto Nacional de Perinatología "Isidro Espinosa de los Reyes"; ${ }^{2}$ Department of Molecular Biology and Biotechnology, \\ Institute of Biomedical Research, Universidad Nacional Autónoma de México; ${ }^{3}$ Gynecologic and Perinatal Endocrinology Coordination, Instituto \\ Nacional de Perinatología "Isidro Espinosa de los Reyes". Mexico City, Mexico
}

\begin{abstract}
Introduction: Breast cancer associated with pregnancy is defined as a malignant neoplasm of the breast that is diagnosed during pregnancy, breastfeeding or one year after delivery. Objective: To analyze perinatal outcomes in a series of young patients with breast cancer and pregnancy in a tertiary care hospital. Methods: Retrospective, analytical study of 26 women younger than 40 years of age with breast cancer who resolved their pregnancy at the National Institute of Perinatology between 2013 and 2018. Clinical-pathological characteristics, perinatal outcomes and family planning methods were studied. Percentages and central tendency measures were obtained, and comparisons were made with the chi-square test or Fisher's exact test. Results: Association of breast cancer with pregnancy was observed in $0.26 \%$ of all births; mean age of presentation was 34 years, $38.4 \%$ of cases had cancer at advanced clinical stages and $57.1 \%$ of the women were treated with modified radical mastectomy; no trend towards higher perinatal complications was observed. Conclusions: Breast cancer associated with pregnancy implies an oncological challenge and does not appear to be a risk factor for adverse perinatal outcomes.
\end{abstract}

KEY WORDS: Breast cancer. Pregnancy. Perinatal care. Contraception. Mexico.

\section{Resultados perinatales en la mujer joven con cáncer de mama y embarazo}

\section{Resumen}

Introducción: El cáncer de mama asociado a embarazo se define como la neoplasia maligna de mama que se diagnostica durante el embarazo, la lactancia o un año después del parto. Objetivo: Analizar los resultados perinatales en una serie de pacientes jóvenes con cáncer de mama y embarazo en un hospital de tercer nivel. Métodos: Estudio analítico retrospectivo de 26 mujeres menores de 40 años con cáncer de mama que resolvieron su embarazo en el Instituto Nacional de Perinatología entre 2013 y 2018. Se estudiaron las características clínico-patológicas, resultados perinatales y métodos de planificación familiar. Se obtuvieron porcentajes y medidas de tendencia central y se realizaron comparaciones con pruebas de chi cuadrada o exacta de Fisher. Resultados: La asociación de cáncer de mama y embarazo se observó en 0.26 \% de todos los nacimientos, la edad media de presentación fue de 34 años, 38.4 \% de los casos cursaba con cáncer en estadio clínico avanzado y $57.1 \%$ de las mujeres fueron tratadas con mastectomía radical modificada; no se apreció tendencia a mayores complicaciones perinatales. Conclusiones: El cáncer de mama asociado a embarazo implica un reto oncológico y no parece ser un factor de riesgo para desenlaces perinatales adversos.

PALABRAS CLAVE: Cáncer de mama. Embarazo. Cuidados perinatales. Anticoncepción. México. 


\section{Background}

Breast cancer is the gynecological neoplasm most frequently associated with pregnancy and puerperium, which is why it constitutes the main cause of mortality from malignant tumors in women. Every year, an estimate of 1.38 million new cases of breast cancer and 458 thousand deaths from this cause are recorded. According to the World Health Organization, approximately $6.5 \%$ of breast malignant neoplasms are diagnosed in women younger than 40 years of age, which corresponds to one in every 206 women, and only $1 \%$ occurs in women younger than 30 years. ${ }^{1,2}$

In Mexico, the National Institute of Statistics, Geography and Informatics reported 16 deaths per 100,000 women aged 20 years and older in 2016; the latest estimates by the International Agency for Research on Cancer indicate that, in 2018, in our country there were 17,486 new cases of breast cancer in women younger than 40 years of age, and that 3,666 women died. ${ }^{3}$

Breast cancer associated with pregnancy is defined as a malignant neoplasm of the breast that is diagnosed during pregnancy, breastfeeding or within one year after delivery; ${ }^{4}$ its incidence is 15 to 35 per 100,000 live births, and mean age at diagnosis is 39 years; incidence could increase due to the current tendency to postpone pregnancy, either for cultural and educational or professional reasons. ${ }^{5}$

\section{Problem statement}

Globally, $10 \%$ of breast cancers are reported to be diagnosed in women younger than 40 years of age during pregnancy; for this reason, every pregnant woman should undergo breast examination at first prenatal care check-up appointment. ${ }^{1,6} \mathrm{~A}$ mammogram abnormal result is usually the main reason for diagnosis in countries with established programs for this pathology; however, patients younger than 40 years are not candidates for routine screening. During pregnancy, the breast shows an increase from 200 to $400 \mathrm{~g}$, which can hinder physical examination and imaging studies interpretation and, for this reason, a palpable breast nodule in pregnant women is usually detected as an incidental finding on physical examination, which persists for more than 2 weeks on average, is indurated with irregular borders and can be associated with thelorrhagia; there is generally an average diagnostic delay of five to 15 weeks, which leads to diagnosing more advanced stages than in non-pregnant population. ${ }^{7,8}$ Diagnosis is made by core needle biopsy, which during gestation is a safe, efficient procedure with minimal adverse effects. ${ }^{9}$

The diagnostic method of choice is breast ultrasound, given that these are young patients in whom reducing radiation exposure is desired; only in case of confirmation of a positive result for malignancy, mammography should be carried out for diagnostic purposes in order to exclude multicentricity or bilateral disease. With the use of abdominal protection, it can be performed with minimal risk in pregnant women. On the other hand, magnetic resonance imaging of the breast is not routinely used, since its interpretation is hampered by changes in the breast associated with pregnancy or breastfeeding. 6.10

Infiltrating ductal carcinoma accounts for $80 \%$ of invasive lesions associated with pregnancy. Receptor expression by immunohistochemistry serves to determine the phenotypic variant of the tumor; generally, pregnancy-related breast cancer has positive estrogen receptors (ERs) in 28 to $58 \%$, positive progesterone receptors (PRs) in 24\%, positive progesterone and estrogen receptors in $16 \%$ and is human epidermal growth factor type 2 (HER2/neu)-positive in 28\%; therefore, during pregnancy, breast cancer luminal phenotype is mostly observed. ${ }^{11}$ In this context, treatment selection depends on the stage of the disease, grade of the primary tumor, ER and PR status of the tumor, HER2/neu overexpression or amplification and histological type. ${ }^{2}$

Regarding the prognosis of pregnancy-associated breast cancer, in past decades, it was associated with poor prognosis; however, in 2013, Amant et al., in an international collaborative study, compared 300 patients diagnosed with breast cancer during pregnancy with 870 women without pregnancy at diagnosis; they found no significant differences in progression or survival $(\mathrm{HR}=1.34 ; 95 \% \mathrm{Cl}=0.93-1.91) .{ }^{12}$ In 2017, lqbal et al. reported a 5 -year survival rate in $82.1 \%$ of patients with breast cancer prior to pregnancy, in comparison with $96.7 \%$ of patients who ended their pregnancy at least 6 months after cancer diagnosis. ${ }^{4}$

The purpose of this study was to analyze the perinatal and contraceptive outcomes in a series of young patients with gestational breast cancer in a tertiary care hospital.

\section{Methods}

An analytical, retrospective case-control study was carried out. In the calculation of the convenience 
sample size, a series of 26 pregnant women younger than 40 years with breast cancer who concluded their pregnancy at the National Institute of Perinatology from May 1, 2013 to December 31, 2018, was reported. The number of control women without breast cancer was determined to be $1 \times 1$. For patient selection, the following criteria were used:

- Inclusion: women younger than 40 years with a single, desired, intrauterine pregnancy who had a breast cancer confirmatory diagnosis; as well as women younger than 40 years with a single intrauterine pregnancy without breast cancer, with the same gestations and same gestational age at admission to prenatal control

- Exclusion: women older than 40 years of age, with a history of any other type of cancer, with multiple pregnancy, unwanted pregnancy, who interrupted gestation or without pregnancy conclusion at the National Institute of Perinatology. In the case of controls, women older than 40 years with high-risk perinatal comorbidities or multiple pregnancy.

Information was obtained through a secondary source (electronic medical record) using a collection form that included a complete medical history, basic laboratory tests, anomaly screening ultrasound and referral to oncology services. All women included in the study were referred from other secondary and tertiary care hospitals with a diagnosis of breast cancer during pregnancy; they received advice on management, follow-up, risks of disease recurrence and progression, treatment options by the oncology department and information on fertility prognostic factors by the family planning department.

The institution's protocol consists of the following:

- Visit 1. Medical record opening and basic laboratory tests (complete blood count, 10-element blood chemistry, blood group, clotting times and urinalysis) were carried out; medical history was obtained and anomaly screening ultrasound was requested, as well as consultation with the maternal-fetal medicine, oncology, social work, nutrition and family planning departments

- Visit 2. Para-clinical test results were explained. Breast cancer treatment during pregnancy, surgical programming and referral to chemotherapy, if necessary, was decided

- Visit 3. Follow-up was provided with the temporality corresponding to patient gestation trimester, and the plan for delivery was established
Table 1. Clinical characteristics of pregnant young women with and without breast cancer

\begin{tabular}{|c|c|c|c|}
\hline Characteristic & $\begin{array}{l}\text { Women with breast } \\
\text { cancer }(n=26)\end{array}$ & Controls $(n=26)$ & $p$ \\
\hline Age, years & $34.54 \pm 4.7$ & $33.27 \pm 8.1$ & 0.49 \\
\hline Gestations, $n$ & $2.73 \pm 1.7$ & $2.69 \pm 1.5$ & 0.93 \\
\hline $\begin{array}{l}\text { Gestational age } \\
\text { at admission, } \\
\text { weeks }\end{array}$ & $19.97 \pm 8.2$ & $17.89 \pm 6.7$ & 0.32 \\
\hline $\begin{array}{l}\text { Body mass } \\
\text { index, } \mathrm{kg} / \mathrm{m}^{2}\end{array}$ & $27.34 \pm 4.6$ & $30.25 \pm 7.0$ & 0.08 \\
\hline
\end{tabular}

- Visit 4. Once pregnancy concluded, women were referred to the family planning department for advice and birth control method follow-up.

Analysis of the obtained information was captured and processed using SPSS statistical program, version 25 (SPSS Inc., IL, Chicago, USA). Descriptive statistical tests, such as frequency, percentages and central tendency measures were carried out. Comparisons between cases and controls were made using Pearson's chi-square test or Fisher's exact test, according to the distribution of each variable.

\section{Results}

In the 2013-2018 period, 26 women with electronic medical records who met the inclusion criteria were identified at the National Institute of Perinatology. Clinical characteristics of the women in the case and control groups are presented in table 1. Among the patients included in the study group, socioeconomic level 1 was the most prevalent and corresponded to $36 \%$; regarding the level of education, women with college and high school degrees predominated. As for gestations, nine women (34.6\%) were primiparous, with a gestational age of 20 weeks at admission. Average age of the women was 34 years, with an age range between 23 and 40 years. Mean body mass index at admission was $27.34 \mathrm{~kg} / \mathrm{m}^{2}$.

The most common histological type was infiltrating ductal carcinoma in $92.4 \%$, followed by mucinous micropapillary carcinoma and malignant phyllodes tumor, both with $3.8 \%$. The most common clinical stage at diagnosis was stage II in $30.8 \%$ of the patients, $38.4 \%$ of the cases corresponded to advanced stages of the disease (clinical stages III and IV) and early 


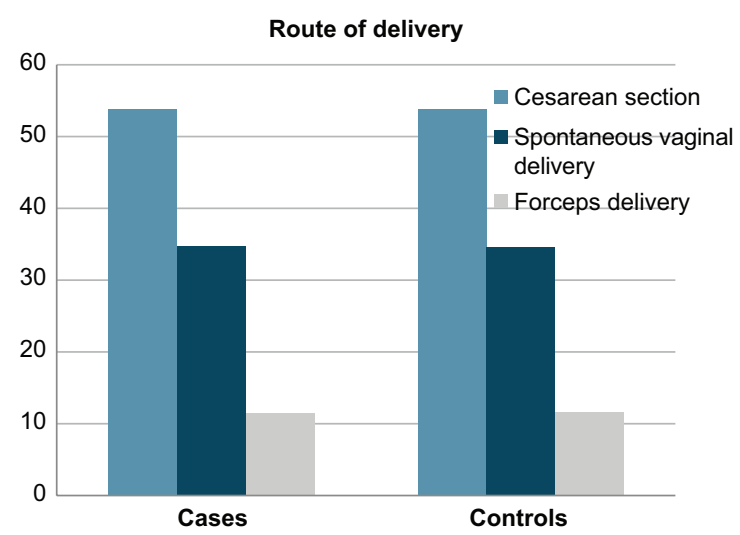

Figure 1. Route of delivery in women diagnosed with breast cancer.

\begin{tabular}{|c|c|c|c|c|c|}
\hline Outcome & \multicolumn{2}{|c|}{$\begin{array}{l}\text { Gestational } \\
\text { breast cancer } \\
(n=26)\end{array}$} & \multicolumn{2}{|c|}{$\begin{array}{l}\text { Control group } \\
\quad(n=26)\end{array}$} & $p$ \\
\hline \multirow{2}{*}{$\begin{array}{l}\text { Gestational age at } \\
\text { delivery (weeks) }\end{array}$} & \multicolumn{2}{|c|}{$37.0 \pm 4.1$} & \multicolumn{2}{|c|}{$38.1 \pm 4.3$} & \multirow[t]{2}{*}{$0.4 \mathrm{C}$} \\
\hline & $\mathrm{n}$ & $\%$ & $\mathrm{n}$ & $\%$ & \\
\hline Preeclampsia & 2 & 7.7 & 4 & 15.4 & 0.33 \\
\hline Preterm delivery & 7 & 26.9 & 5 & 19.2 & 0.51 \\
\hline Gestational diabetes & 1 & 3.8 & 5 & 19.2 & 0.17 \\
\hline Obstetric hemorrhage & 2 & 7.7 & 2 & 7.7 & 0.50 \\
\hline $\begin{array}{l}\text { Newborn small for } \\
\text { gestational age }\end{array}$ & 4 & 15.4 & 2 & 7.7 & 0.33 \\
\hline 1-min Apgar score & 8 & 89.3 & 8 & 86.3 & 0.17 \\
\hline 5-min Apgar score & 9 & 98.9 & 9 & 96.3 & 0.32 \\
\hline
\end{tabular}

stages accounted for $30.8 \%$ of cases $(15.4 \%$ at stage 0 and $15.4 \%$ at stage I).

Regarding treatment, $57.1 \%$ underwent modified radical mastectomy and $23.8 \%$ received breast-conserving treatment (quadrantectomy); $34.6 \%$ of the patients received chemotherapy after week 18 of gestation, and once pregnancy was over, they continued their management in the referring cancer center.

During prenatal control, 26.9 and $23.1 \%$ received follow-up with three and four ultrasounds, respectively, in comparison with the control group ( $p=0.43$ ), in which $38.5 \%$ underwent two ultrasounds and $11.5 \%$ only one obstetric ultrasound practiced by the Maternal-fetal Medicine Department.
Figure 1 shows the routes of delivery in cases and controls. In $53.8 \%$ of the patients with gestational breast cancer, delivery was by cesarean section; in $88.4 \%$, the indication was elective and, in $11.6 \%$, iterative. In $46.2 \%$ of the patients, delivery was via the vaginal route; in $19.3 \%$, by labor induction; in $15.4 \%$, by spontaneous vaginal delivery and in $11.5 \%$, delivery was assisted by forceps. In the control group, $53.8 \%$ of deliveries were by cesarean section; in $34.6 \%$, by spontaneous vaginal delivery, and in $11.6 \%$, delivery was assisted by forceps; there was no labor induction in the control group.

Perinatal outcomes are described in table 2, in which gestational age at delivery is described to have been similar in cases and controls (37 to 38 weeks), with the most common complication in the group of women with breast cancer being preterm delivery (26.9\%), followed by preeclampsia and obstetric hemorrhage, both accounting for $7.7 \%$. Regarding neonatal outcomes, $15 \%$ of newborns were classified as small for gestational age; only one malformation was described in the group of cases involving microcephaly in a patient with a history of chemotherapy administration with fluorouracil, doxorubicin and cyclophosphamide regimen. Pregnancy-associated complications were similar in the control group, as were Apgar score results at 1 and 5 minutes.

The most commonly used contraceptive method by patients with cancer and pregnancy was bilateral tubal ligation (BTL) in $65.4 \% ; 15.5 \%$ did not choose any method; bilateral salpingo-oophorectomy was the method in $11.5 \%$ and, finally, copper intrauterine device in $7.6 \%$. In turn, $40.3 \%$ of the control group chose copper intrauterine device, $30.8 \%$ selected BTL and, in comparison with the group of cases ( $p=0.13$ ), $21.3 \%$ used no method, $3.8 \%$ used progestins, $3.8 \%$ combined oral contraceptives and no salpingo-oophorectomy was performed in any case.

\section{Discussion}

Over the past 10 years, the number of young women with gestational breast cancer has significantly increased; owing to this, multidisciplinary approach to the management of these patients has gained relevance. Breast cancer associated with pregnancy is a rare entity that implies an oncological challenge due to the form of presentation; in our study, it accounted for $0.26 \%$ of all births recorded at the National Institute of Perinatology from 2013 to 2018. This study shows the perinatal outcomes in a tertiary care institution 
compared to those of a control group matched by maternal age, number of gestations and gestational age at admission to the Institute. One more factor to consider is the socioeconomic level of the women referred from primary and secondary care hospitals. Low socioeconomic level characterized the women as a vulnerable population, since this condition limits their opportunities to receive comprehensive treatment.

Currently, the approach to young women with breast cancer diagnosed during pregnancy or breastfeeding can be highly heterogeneous. At the time of diagnosis, $38.4 \%$ of the patients were at advanced clinical stages, similar to those referred in different published series, given the changes that occur during pregnancy.,13

The most common surgical approach was modified radical mastectomy, similar to that reported by Durrani et al. in 2018; surgery is a safe method during pregnancy and has been associated with minimal fetal risks. ${ }^{6}$ In our review, $57.1 \%$ of patients were treated with modified radical mastectomy. We consider that this was due to the percentage of cases diagnosed at first and second trimester, which justifies the treatment decision. If the date of pregnancy conclusion is during the third trimester, breast-conserving surgery can be carried out followed by radiotherapy in the puerperium, without patient survival being altered. ${ }^{14}$ In our study, 23.8\% underwent breast-conserving surgery at third trimester of pregnancy, similar to that described by Gentilini et al. in 2010.

In patients receiving chemotherapy during pregnancy, development of preeclampsia, preterm labor, and low birth weight have been described:5,6 however, in our series of patients, no significant difference was observed with the group of patients who underwent chemotherapy.

Our study did not show perinatal complications in the group of women with breast cancer such as preterm delivery $(26.9 \%$ vs. $19.2 \%$; $p=0.51)$, preeclampsia (7.7\% vs. $15.4 \% ; p=0.33)$, gestational diabetes $(3.8 \%$ vs. $19.2 \% ; p=0.17)$ and obstetric hemorrhage $(7.7 \%$ vs. $7.7 \% ; p=0.50$ ). From the above, our results indicate that the incidence of low birth weight or alterations in Apgar assessment score at 1 and 5 min did not differ from those observed in the control group.

Of the 26 patients with cancer and pregnancy, $58.8 \%$ had their delivery via cesarean section and the rest by vaginal route. In 2018, Ramírez et al. described their experience, in which pregnancies were resolved under the premise of safe cesarean section and thus reduced birth-associated morbidities; in our series, we recommended that the delivery decision should be based on obstetric factors, since breast cancer diagnosis does not imply a specific delivery route..$^{15}$
In young women, selection of a birth control method is essential, since after cancer treatment they will continue to be fertile, which is why patients are advised to postpone pregnancy for at least 2 years after treatment. ${ }^{4,5}$ Although our sample is limited, a tendency was observed in patients with breast cancer, even in those who were at their first pregnancy, for opting for definitive birth control methods, such as bilateral tube ligation ( $p=0.013$ ). In 2016, Güth et al. found that the rate of unwanted pregnancy within the first year after breast cancer diagnosis was $3.5 \%$, which is why providing contraceptive counselling during prenatal care is compulsory. Up to $50 \%$ of the patients at the time of cancer diagnosis referred not having completed their childbearing plans.

The National Institute of Perinatology is a national reference center for cancer and pregnancy; however, our study has some limitations, such as its retrospective nature, limited representativeness of the sample, which is restricted to a single institution, and the low prevalence of the disease; in addition, we have no longterm oncological follow-up of the patients, which is an aspect to be addressed in the future in our institution.

It is important to point out that breast cancer associated with pregnancy is an entity whose incidence is increasing. Evidence supports that treatment during pregnancy can be carried out safely for the mother and the fetus, and we can conclude that pregnancy is not a risk factor for adverse perinatal outcomes.

\section{Acknowledgements}

The authors thank the National Institute of Perinatology.

\section{Conflict of interests}

The authors declare that there are no conflicts of interest.

\section{Funding}

The authors declare that the present article has been self-financed.

\section{Ethical disclosures}

Protection of human and animal subjects. The authors declare that no experiments were performed on humans or animals for this research. 
Confidentiality of data. The authors declare that they followed the protocols of their work center on the publication of patient data.

Right to privacy and informed consent. The authors declare that no patient data appear in this article.

\section{References}

1. Ma KK, Preusse CJ, Stevenson PA, Winget VL, McDougall JA, Li Cl, et al. Obstetric outcomes in young women with breast cancer: prior postpartum, and subsequent pregnancies. Am J Perinatol. 2020;37:370-4.

2. Rosenberg SM, Partridge AH. Management of breast cancer in very young women. Breast. 2015;24:S154-8.

3. Consenso Mexicano sobre Diagnóstico y Tratamiento del Cáncer Mamario. Sexta Revisión. Mexico: Elsevier; 2015.s

4. Iqbal J, Amir E, Rochon PA, Giannakeas V, Sun P, Narod SA. Association of the timing of pregnancy with survival in women with breast cancer. JAMA Oncol. 2017;3:659-65.

5. Knabben L, Mueller MD. Breast cancer and pregnancy. Horm Mol Biol Clin Investig. 2017;32:26.

6. Durrani S, Akbar S, Heena H. Breast cancer during pregnancy. Cureus. 2018;10:e2941.

7. American Cancer Society. Cancer Facts and Figures 2019. United States: American Cancer Society; 2019.
8. Esserman LJ, Shieh Y, Rutgers EJ, Knauer M, Retel VP, Mook S, et al. Impact of mammographic screening on the detection of good and poor prognosis breast cancers. Breast Cancer Res Treat. 2011;130:725-34.

9. Dizon DS, Tejada-Berges T, Steinhoff MM, Sung J, Cain J. Breast cancer. In: Barakat RR, Markman M, Randall ME, editors. Principles and Practice of Gynecologic Oncology. United States: Lippincott, Williams and Wilkins; 2009.

10. Shah NM, Scott DM, Kandagatla P, Moravek MB, Cobain EF, Burness ML, et al. Young women with breast cancer: fertility preservation options and management of pregnancy-associated breast cancer. Ann Surg Oncol. 2019;26:1214-24.

11. Kohler BA, Sherman RL, Howlader N, Jemal A, Blythe-Ryerson A, Henry KA, et al. Annual report to the nation on the status of cancer, 1975-2011, featuring incidence of breast cancer subtypes by race/ethnicity, poverty, and state. J Natl Cancer Inst. 2015;107:djv048.

12. Amant F, von Minckwitz G, Han SN, Bontenbal M, Ring AE, Giermek J, et al. Prognosis of women with primary breast cancer diagnosed during pregnancy: results from an international collaborative study. J Clin Oncol. 2013;31:2532-9.

13. Lambertini M, Viglietti G. Pregnancies in young women with diagnosis and treatment of HER2-positive breast cancer. Oncotarget. 2019;10:803-4.

14. Amant F, Deckers S, van Calsteren K, Loibl S, Halaska M, Brepoels L, et al. Breast cancer in pregnancy: recommendations of an international consensus meeting. Eur J Cancer. 2010;46:3158-68.

15. Gómez-Hidalgo NR, Mendizabal E, Joigneau L, Pintado $P$, de León-Luis J. Breast cancer during pregnancy: results of maternal and perinatal outcomes in a single institution and systematic review of the literature. J Obstet Gynaecol. 2019;39:27-35. 